\title{
Transient hyperlactatemia during intravenous administration of glycerol: a prospective observational study
}

Shinshu Katayama* ${ }^{*}$, Ken Tonai, Yuya Goto, Kansuke Koyama, Toshitaka Koinuma, Jun Shima, Masahiko Wada and Shin Nunomiya

\begin{abstract}
Background: Intravenous glycerol treatment, usually administered in the form of a 5\% fructose solution, can be used to reduce intracranial pressure. The administered fructose theoretically influences blood lactate levels, although little is known regarding whether intravenous glycerol treatment causes transient hyperlactatemia. This study aimed to evaluate blood lactate levels in patients who received intravenous glycerol or mannitol.

Methods: This single-center prospective observational study was performed at a 14-bed general intensive care unit between August 2016 and January 2018. Patients were excluded if they were $<20$ years old or had pre-existing hyperlactatemia (blood lactate $>2.0 \mathrm{mmol} / \mathrm{L}$ ). The included patients received intravenous glycerol or mannitol to reduce intracranial pressure and provided blood samples for lactate testing before and after the drug infusion (before the infusion and after $15 \mathrm{~min}, 30 \mathrm{~min}, 45 \mathrm{~min}, 60 \mathrm{~min}, 90 \mathrm{~min}, 120 \mathrm{~min}$, and $150 \mathrm{~min}$ ).

Results: Among the 33 included patients, 13 patients received $200 \mathrm{~mL}$ of glycerol over $30 \mathrm{~min}$, 13 patients received $200 \mathrm{~mL}$ of glycerol over $60 \mathrm{~min}$, and 7 patients received $300 \mathrm{~mL}$ of mannitol over $60 \mathrm{~min}$. Both groups of patients who received glycerol had significantly higher lactate levels than the mannitol group $(2.8 \mathrm{mmol} / \mathrm{L}$ vs. $2.2 \mathrm{mmol} / \mathrm{L}$ vs. $1.6 \mathrm{mmol} / \mathrm{L}, P<0.0001)$, with the magnitude of the increase in lactate levels corresponding to the glycerol infusion time. There were no significant inter-group differences in cardiac index, stroke volume, or stroke volume variation. In the group that received the 30-min glycerol infusion, blood lactate levels did not return to the normal range until after $120 \mathrm{~min}$.
\end{abstract}

Conclusions: Intravenous administration of glycerol leads to higher blood lactate levels that persist for up to 120 min. Although hyperlactatemia is an essential indicator of sepsis and/or impaired tissue perfusion, physicians should be aware of this phenomenon when assessing the blood lactate levels.

Keywords: Glycerol, Hyperlactatemia, Intensive care unit, Mannitol

\section{Background}

Lactate is a sensitive indicator of tissue perfusion and metabolism that helps quantify the balance between aerobic and anaerobic metabolism [1-3]. In addition, lactate is correlated with intravascular volume and sepsis status and is associated with circulatory shock severity [4-6]. In this context, lactate levels of $>2.0 \mathrm{mmol} / \mathrm{L}$ are

\footnotetext{
*Correspondence: shinsyu_k@jichi.ac.jp

Division of Intensive Care, Department of Anesthesiology and Intensive Care Medicine, Jichi Medical University School of Medicine, 3311-1, Yakushiji, Shimotsuke, Tochigi 329-0498, Japan
}

included in the Sepsis-3 criteria for septic shock [7], and lactate level measurements are widely recognized as important in the critical care setting. In clinical practice, it is recommended that attempts be made to increase cardiac output using fluid resuscitation or inotropes, which is called lactate-guided resuscitation [8-11].

Intravenous glycerol treatment can be used to reduce intracranial pressure and is usually administered in the form of a $5 \%$ fructose solution with concentrated glycerin. Despite low-quality evidence of the efficacy [12, 13], glycerol is widely used in Japan for patients with acute stroke 
or brain trauma, without significant side effects [14]. Although children with some congenital metabolic diseases experience hyperlactatemia (i.e., congenital glycerin metabolic disorders), little is known about intravenous glycerol-induced hyperlactatemia [15]. However, fructose can theoretically influence lactate metabolism [16, 17], and lactate levels might change during the administration of glycerol, which could lead to a misdiagnosis or overestimation of disease severity. Therefore, the present study evaluated the blood lactate levels in patients who received intravenous glycerol or mannitol and whether the rate of the intravenous glycerol infusion influenced blood lactate concentrations.

\section{Methods}

This single-center, prospective, observational study was performed at a 14-bed general intensive care unit in a university hospital (Tochigi, Japan). The study protocol was approved by the institutional ethics committee of Jichi Medical University Hospital (16-120). Written informed consent was obtained from the participants or their nearest relatives.

\section{Participants}

This study included patients who were admitted to the intensive care unit and received intracranial pressure-reducing therapy using intravenous glycerol or mannitol between August 2016 and January 2018. Patients were excluded if they were $<20$ years old, had an end-stage renal failure and were receiving chronic dialysis, had hepatic dysfunction, or had abnormal lactate levels $(>2.0 \mathrm{mmol} / \mathrm{L})$ before starting the intracranial pressure-reducing therapy.

\section{Administration of glycerol or mannitol}

The intravenous glycerol (GLYCEREB ${ }^{\circ}$; Terumo, Japan) was administered at a volume of $200 \mathrm{~mL}$ over $30 \mathrm{~min}$ or $60 \mathrm{~min}$. The intravenous mannitol (20\% MANNITOL INJECTION $^{\odot}$; Yoshindo, Japan) was administered at a volume of $300 \mathrm{~mL}$ over $60 \mathrm{~min}$. The selection of the drug and infusion rate was made by the attending physician.

\section{Lactate measurement}

Blood samples were obtained for lactate measurements at eight time points (before the infusion and after $15 \mathrm{~min}$, $30 \mathrm{~min}, 45 \mathrm{~min}, 60 \mathrm{~min}, 90 \mathrm{~min}, 120 \mathrm{~min}$, and $150 \mathrm{~min}$ ) and were immediately transferred to the laboratory for testing. The blood gas analyses, which included lactate measurements, were performed using an ABL800 FLEX device (Radiometer Medical ApS, Denmark) or a RAPIDLAB1265 device (Siemens Healthcare Diagnostics Inc., Tarrytown, NY, USA).

\section{Data collection}

The following information was collected for all patients: age, sex, body weight, body height, present disease, Acute Physiology and Chronic Health Evaluation II (APACHE II) score [18], and Sequential Organ Failure Assessment (SOFA) score [19]. We also recorded data regarding the requirement for mechanical ventilation and the 28-day survival status. A FloTrac device (version 1.5, Edwards LifeSciences, Irvine, USA) was used to measure cardiac index (CI), stroke volume index (SVI), and stroke volume variation (SVV).

\section{Statistical analysis}

Variables were compared among these groups using Pearson's chi-square test, the Kruskal-Wallis test, or the Steel-Dwass test as appropriate. All analyses were performed using JMP software (version 13; SAS Institute Inc., Cary, NC, USA). Data were presented as median and interquartile range or as number and percentage. Differences were considered statistically significant at $P$ values of $<0.05$.

\section{Results \\ Enrollment and baseline characteristics}

During the study period, 37 patients were enrolled and 4 patients were excluded based on the pre-existing high lactate levels $(>2.0 \mathrm{mmol} / \mathrm{L})$. The characteristics of the 33 included patients are summarized in Table 1. Thirteen patients received $200 \mathrm{~mL}$ of glycerol over $30 \mathrm{~min}, 13$ patients received $200 \mathrm{~mL}$ of glycerol over $60 \mathrm{~min}$, and 7 patients received $300 \mathrm{~mL}$ of mannitol over $60 \mathrm{~min}$. Although the groups' APACHE II and SOFA scores were not significantly different, the group that received a 30-min glycerol infusion had a significantly lower 28-day survival rate compared to the other two groups $(69.2 \%$ vs. $100 \%$ vs. $100 \% ; P=0.03)$. Table 2 shows the laboratory findings from before the start of the infusions, with no evidence of significant inter-group differences. There were no significant differences in parameters of hepatic function between the groups.

Comparing the groups that received glycerol or mannitol Both groups of patients who received glycerol had significantly higher lactate levels than the mannitol group $(2.8 \mathrm{mmol} / \mathrm{L}$ vs. $2.2 \mathrm{mmol} / \mathrm{L}$ vs. $1.6 \mathrm{mmol} / \mathrm{L}$, respectively; $P<0.0001$ ), with the magnitude of the increase in lactate levels corresponding to the glycerol infusion time. Compared to the mannitol group, the 30-min glycerol group had significantly higher lactate levels at all measured time points between 15 and $120 \mathrm{~min}$, and all of these patients had high lactate levels $(>2.0 \mathrm{mmol} / \mathrm{L})$ during the infusions. The 60-min glycerol group had significantly higher lactate levels at the 45-min and 60-min measurements, relative to the mannitol group, and 9 patients $(69.2 \%)$ in the 60 -min glycerol group 
Table 1 Patient characteristics

\begin{tabular}{|c|c|c|c|c|}
\hline & $\begin{array}{l}\text { Glycerol } 200 \mathrm{~mL} / 30 \mathrm{~min} \\
n=13\end{array}$ & $\begin{array}{l}\text { Glycerol } 200 \mathrm{~mL} / 60 \mathrm{~min} \\
n=13\end{array}$ & $\begin{array}{l}\text { Mannitol } 300 \mathrm{~mL} / 60 \mathrm{~min} \\
n=7\end{array}$ & $P$ value \\
\hline Age, years & $57(47-66)$ & $46(38-69)$ & $58(45-62)$ & 0.592 \\
\hline Male, sex & $6(46.1 \%)$ & $5(38.5 \%)$ & $4(57.2 \%)$ & 0.724 \\
\hline Height, cm & $161(154-166)$ & 155 (154-164) & $170(155-170)$ & 0.229 \\
\hline Body weight, kg & $60(51-65)$ & $60(55-69)$ & $62(54-67)$ & 0.731 \\
\hline Body mass index, $\mathrm{kg} / \mathrm{m}^{2}$ & $23.9(19.4-25.7)$ & $25.0(21.2-26.9)$ & $21.7(21.1-27.9)$ & 0.573 \\
\hline Diseases, \% & & & & 0.426 \\
\hline Brain tumor & $7.7 \%$ & $23.1 \%$ & $0.0 \%$ & \\
\hline Intracranial hemorrhage & $15.4 \%$ & $23.1 \%$ & $14.3 \%$ & \\
\hline Sub-arachnoid hemorrhage & $23.1 \%$ & $7.7 \%$ & $42.9 \%$ & \\
\hline Cerebral infarction & $38.5 \%$ & $38.5 \%$ & $28.6 \%$ & \\
\hline Traumatic brain injury & $0.0 \%$ & $7.7 \%$ & $14.3 \%$ & \\
\hline Other & $15.4 \%$ & $0.0 \%$ & $0.0 \%$ & \\
\hline IHD & $7.7 \%$ & $0.0 \%$ & $0.0 \%$ & 0.452 \\
\hline $\mathrm{CHF}$ & $0.0 \%$ & $15.4 \%$ & $0.0 \%$ & 0.194 \\
\hline Atrial fibrillation & $15.4 \%$ & $15.4 \%$ & $0.0 \%$ & 0.542 \\
\hline Diabetes mellitus & $15.4 \%$ & $23.1 \%$ & $14.3 \%$ & 0.840 \\
\hline Hypertension & $30.8 \%$ & $23.1 \%$ & $42.9 \%$ & 0.655 \\
\hline APACHE ॥ & $19(13-22)$ & $16(13-28)$ & $18(11-22)$ & 0.858 \\
\hline 28-day survival, \% & $69.2 \%$ & $100.0 \%$ & $100.0 \%$ & 0.030 \\
\hline
\end{tabular}

APACHE II Acute Physiology and Chronic Health Evaluation II score, CHF chronic heart failure, IHD ischemic heart disease

had high lactate levels during the infusions. None of the patients in the mannitol group had high lactate levels during the infusions ( $100 \%$ vs. $69.2 \%$ vs. $0.0 \%$, respectively; $P<0.0001$ ) (Fig. 1). None of the patients exhibited signs of intravenous hemolysis.

\section{Hemodynamics and blood gas analyses}

During the glycerol or mannitol treatment, no significant inter-group differences were observed in terms of $\mathrm{CI}, \mathrm{SVI}, \mathrm{SVV}, \mathrm{pH}$, or $\mathrm{HCO}_{3}{ }^{-}$levels (Figs. 2 and 3$)$.

Table 2 Laboratory findings immediately before the administration of intracranial pressure-reducing agents

\begin{tabular}{|c|c|c|c|c|}
\hline & Glycerol $200 \mathrm{~mL} / 30 \mathrm{~min}$ & Glycerol $200 \mathrm{~mL} / 60 \mathrm{~min}$ & Mannitol $300 \mathrm{~mL} / 60 \mathrm{~min}$ & $P$ value \\
\hline WBC, $10^{9} / \mathrm{L}$ & $12.5(10.2-14.7)$ & $10.1(9.1-12.2)$ & $1.4(8.1-13.4)$ & 0.228 \\
\hline $\mathrm{Hb}, \mathrm{g} / \mathrm{dL}$ & $9.5(8.6-11.3)$ & $8.2(7.8-10.4)$ & $9.4(8.9-10.0)$ & 0.256 \\
\hline CRP, mg/dL & $8.1(3.8-14.5)$ & $5.7(0.7-9.5)$ & $5.1(2.7-9.5)$ & 0.271 \\
\hline Alb, g/dL & $2.3(2.1-2.7)$ & $2.6(2.3-3.2)$ & $3.0(2.5-3.4)$ & 0.143 \\
\hline $\mathrm{BUN}, \mathrm{mg} / \mathrm{dL}$ & $10(9-13)$ & $12(8-19)$ & $14(10-16)$ & 0.502 \\
\hline Creatinine, mg/dL & $0.67(0.49-0.87)$ & $0.51(0.43-1.11)$ & $0.61(0.50-0.97)$ & 0.790 \\
\hline T-Bil, mg/dL & $0.75(0.47-1.08)$ & $0.95(0.56-1.68)$ & $1.01(0.67-1.24)$ & 0.420 \\
\hline AST, U/L & $28(18-48)$ & $26(21-37)$ & $29(23-83)$ & 0.634 \\
\hline$A L T, U / L$ & $18(13-37)$ & $19(14-43)$ & $20(15-57)$ & 0.699 \\
\hline $\mathrm{LDH}, \mathrm{U} / \mathrm{L}$ & $249(182-328)$ & $231(166-269)$ & $216(182-246)$ & 0.530 \\
\hline$P, \mathrm{mg} / \mathrm{dL}$ & $2.6(2.0-2.8)$ & $2.8(1.9-3.3)$ & $2.7(2.2-3.1)$ & 0.828 \\
\hline ChE, U/L & $205(155-234)$ & $139(115-185)$ & $195(79-232)$ & 0.211 \\
\hline SOFA & $3(2-5)$ & $6(3-7)$ & $3(3-4)$ & 0.182 \\
\hline Mechanical ventilation & $46.1 \%$ & $76.9 \%$ & $71.4 \%$ & 0.235 \\
\hline
\end{tabular}




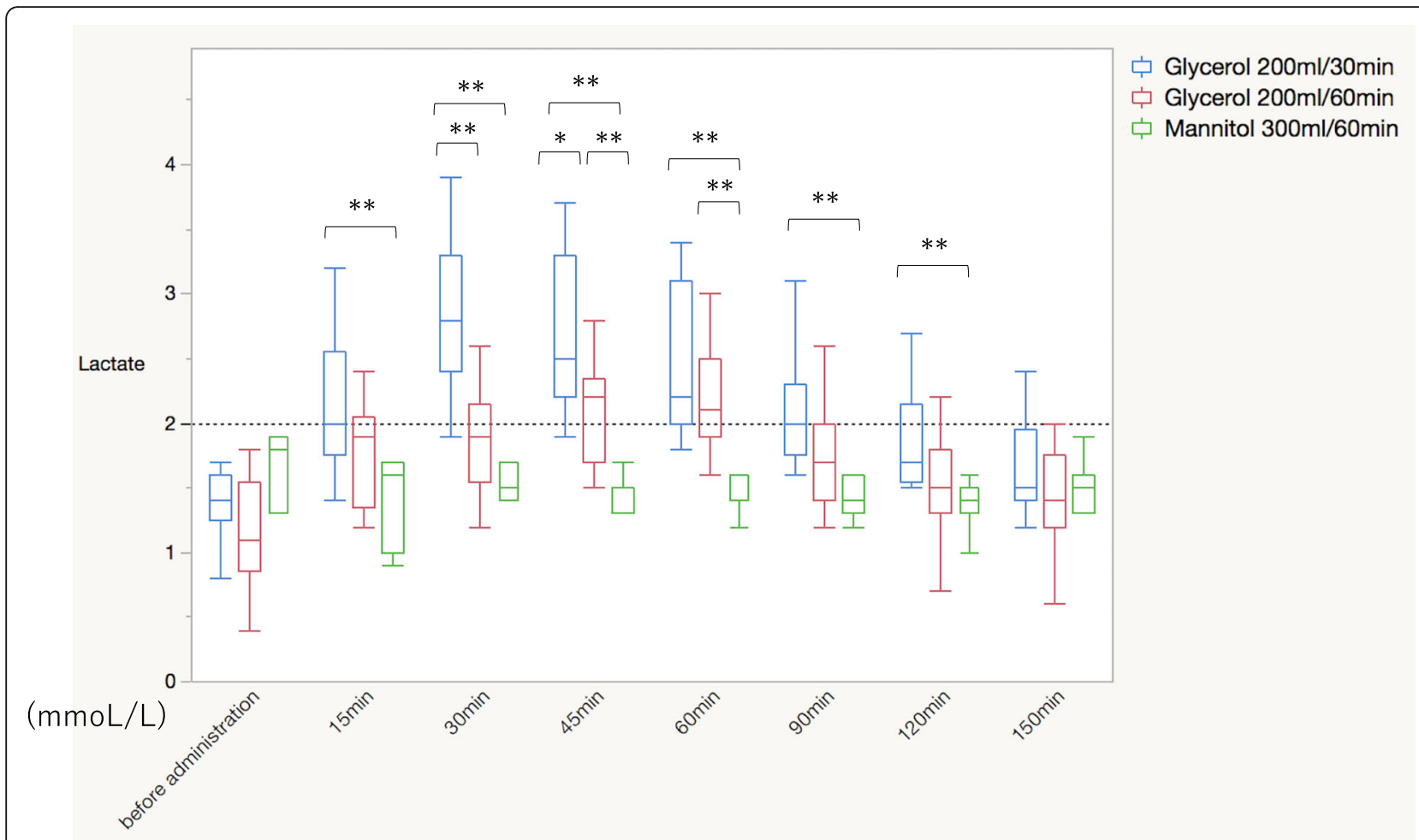

Fig. 1 Blood lactate dynamics during the administration of glycerol or mannitol. Horizontal dot line means the upper normal limit of blood lactate level. ${ }^{*} P<0.05,{ }^{*} P<0.01$

\section{Discussion}

The present study revealed that intravenous glycerol treatment increased the lactate levels in all patients, and $84.6 \%$ of these patients developed lactate levels of > $2.0 \mathrm{mmol} / \mathrm{L}$. This study also revealed that lactate levels differed significantly according to the duration of glycerol infusion. However, intravenous mannitol treatment did not influence the lactate levels, and there were no inter-group differences in cardiac output and stroke volume parameters. Therefore, the effects of osmotic diuresis seem unrelated to the increased lactate levels.

Hyperlactatemia during glycerol administration is caused by the fructose that is added to the glycerol solution. Intravenously administered fructose is metabolized by the liver and converted by fructokinase into fructose-1-phosphate, which then enters the glycolytic or gluconeogenesis cycle before being metabolized into lactate, glucose, or glycogen. Fructokinase activity remains unchanged in a state of insulin deficiency, and fructose is quickly metabolized, which causes pyruvate accumulation. This occurs even in the presence of reduced glucose tolerance because fructose metabolism does not involve glucokinase or phosphofructokinase, which has decreased the activities in an insulindeficient state. Furthermore, metabolism of fructose into pyruvate in the liver is rapid enough to cause significant accumulation of un-metabolized pyruvate by the tricarboxylic acid cycle, which causes hyperlactatemia. Approximately
$30 \%$ of the administered fructose is converted into glucose [17], with the intravenous fructose stimulating splanchnic lactate release both at rest [16] and during exercise [20], as well as glucose-stimulated extrasplanchnic lactate production [21]. Moreover, the lactate concentration increases that are induced by fructose are positively correlated with muscle glycogen resynthesis [22], which accelerates nucleic acid turnover and uric acid production, and then causes hyperlactatemia [23].

The fructose infusion rate should not exceed $0.3 \mathrm{~g} / \mathrm{kg} / \mathrm{h}$ [24], and the recommended glycerol infusion rate should not exceed $300 \mathrm{~mL}$ over $30 \mathrm{~min}$ for a $60-\mathrm{kg}$ patient, as rapid glycerol administration increases the risk of intravascular hemolysis [25]. It has been shown that administering $0.5 \mathrm{~g} /$ $\mathrm{kg}$ glycerol for $90 \mathrm{~min}$ is superior to $30 \mathrm{~min}$ for reducing intracranial pressure [26]. Although the present study did not measure haptoglobin to quantify hemolysis, we did not detect any apparent signs of intravascular hemolysis among the included patients. However, we found that the increase in lactate levels was larger at higher infusion rates. Thus, physicians should be aware of this phenomenon and ideally wait for at least $120 \mathrm{~min}$ when assessing the illness severity in patients who received glycerol. Conversely, the glycerol infusion rate should be moderated and lactate levels tested frequently in patients with pre-existing hyperlactatemia.

Hyperlactatemia can occur under several physiological conditions, although it is often correlated with oxygen 

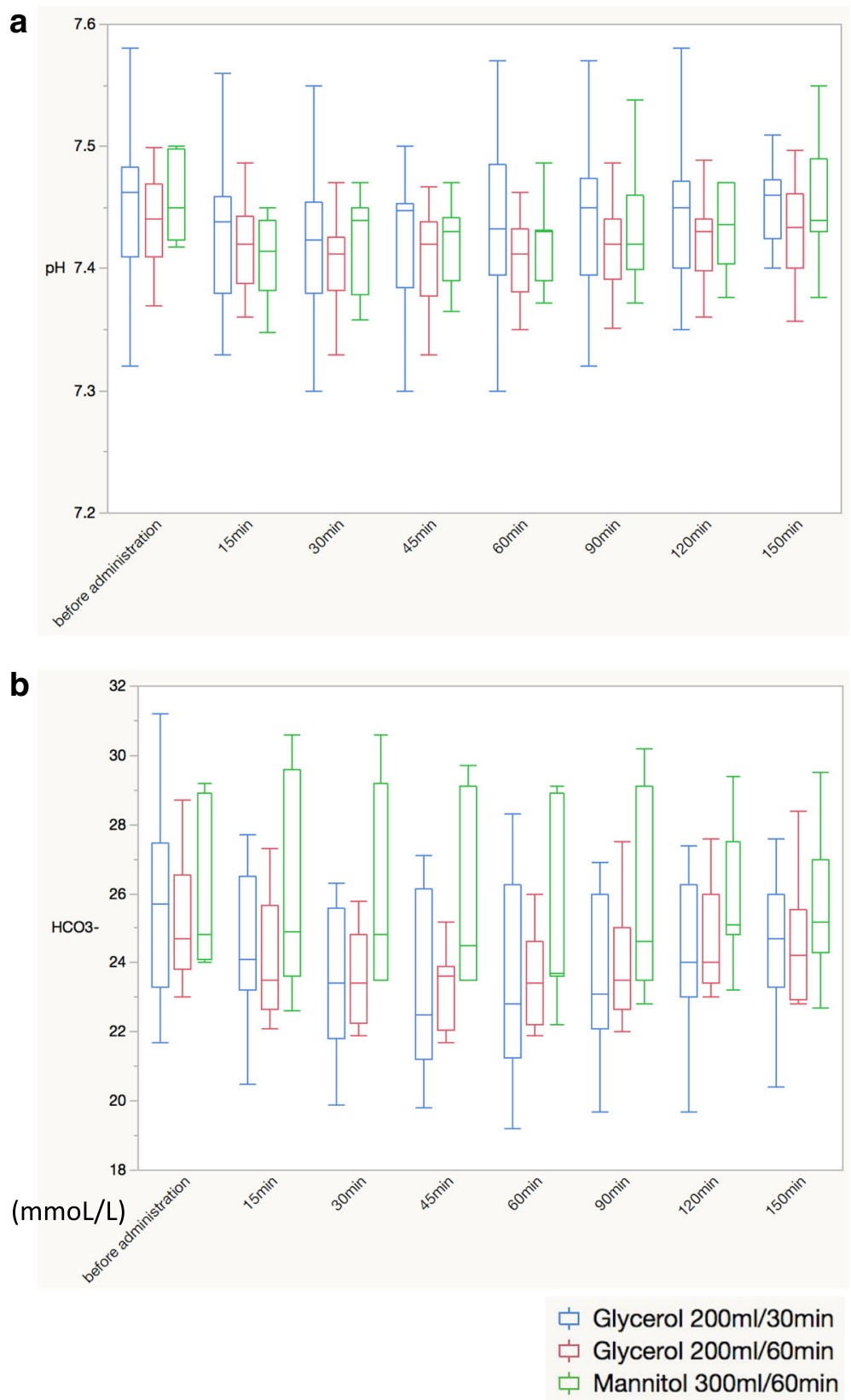

Fig. 2 Acid-base status during the administration of glycerol or mannitol. a $\mathrm{pH} . \mathbf{b} \mathrm{HCO}_{3}{ }^{-}$

delivery, cardiac function, intravascular volume, and hemoglobin levels. For example, hemodynamically unstable patients are likely to present with increased lactate levels. In this context, agents that reduce intracranial pressure (e.g., glycerol or mannitol) induce strong osmotic diuresis that can cause reduced stroke volume and intravascular volume that lead to elevated lactate levels. However, the present study did not detect significant relationships between the various hemodynamic parameters and hyperlactatemia, and none of the patients developed active bleeding or desaturation during the administration of glycerol or mannitol. Therefore, it appears unlikely that hyperlactatemia caused by intravenous glycerol administration is related to impaired hemodynamics or oxygen delivery.

The present study has several limitations. First, this was a small single-center observational study; nevertheless, we were still able to detect a significant relationship between intravenous glycerol treatment and elevated blood lactate levels. Second, we did not evaluate whether the patients had congenital metabolic disorders, although these conditions are very rare. Finally, we did not evaluate 


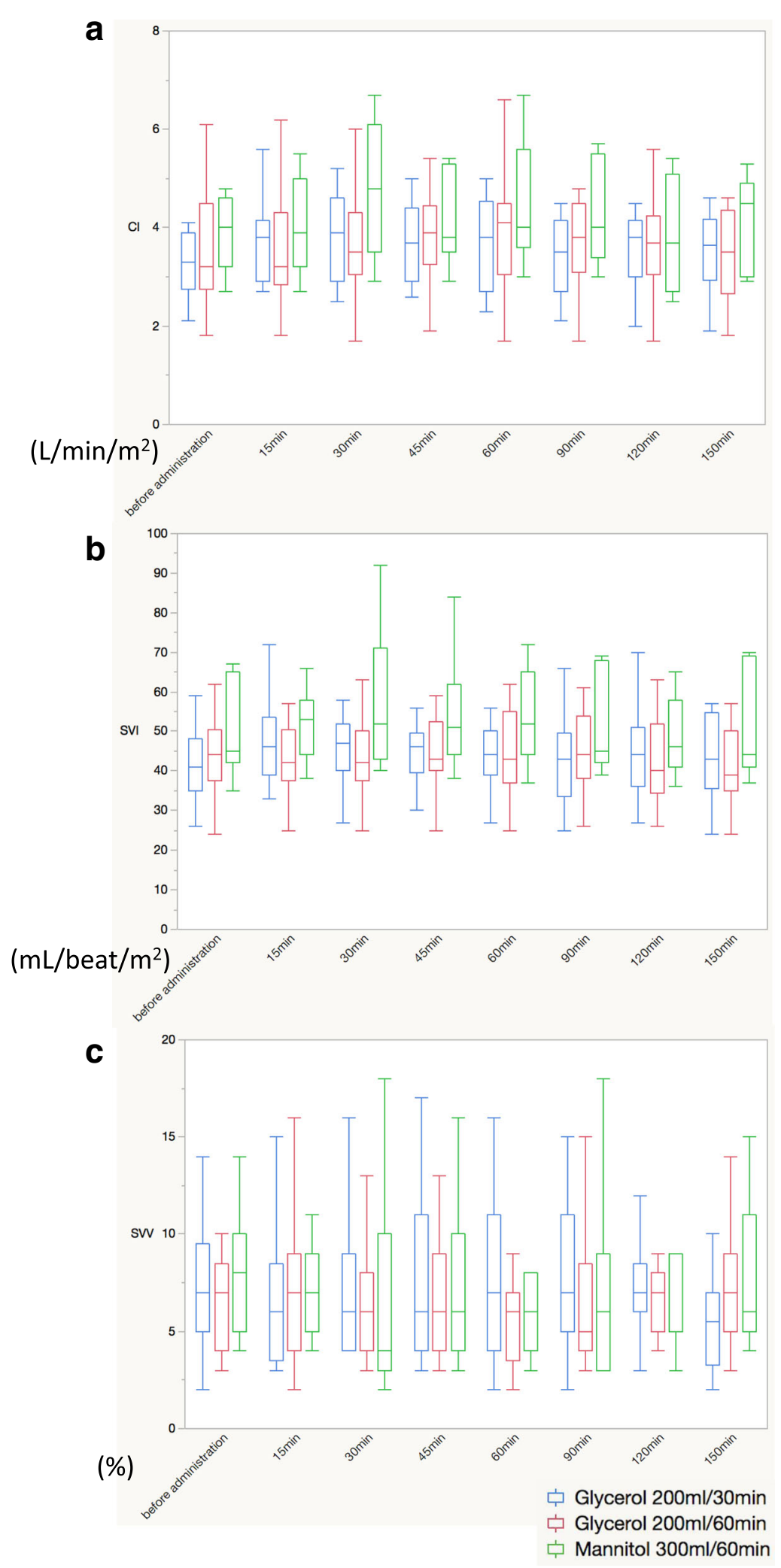

Fig. 3 Hemodynamics during the administration of glycerol or mannitol. a Cardiac index. b Stroke volume index. c Stroke volume variation 
any increases in lactate levels among patients with pre-existing hyperlactatemia (who were excluded from the study). Although the effects of glycerol on lactate levels disappeared after at least $120 \mathrm{~min}$ had passed in patients with normal baseline lactate levels, it is plausible that in patients with hyperlactatemia, the effects of glycerol may be prolonged past $120 \mathrm{~min}$ due to the impaired lactate metabolism, thus warranting a longer observation period than used in this study. Therefore, further studies are needed to evaluate blood lactate levels during glycerol administration in patients with pre-existing hyperlactatemia.

\section{Conclusions}

Intravenous administration of glycerol induced an increase in blood lactate levels that persisted for up to $120 \mathrm{~min}$. Although hyperlactatemia is an essential indicator of sepsis and/or impaired tissue perfusion, this phenomenon should be considered when assessing the blood lactate levels.

\section{Abbreviations}

APACHE II: Acute Physiology and Chronic Health Evaluation II; Cl: Cardiac index; SOFA: Sequential Organ Failure Assessment; SVI: Stroke volume index; SW: Stroke volume variation

\section{Acknowledgements}

We acknowledge the assistance of the intensive care nursing staff at Jichi Medical University Hospital, Tochigi, Japan.

\section{Funding}

The study was supported by research funding from Jichi Medical University.

\section{Availability of data and materials}

The dataset generated and/or analyzed during the current study is not publicly available, although anonymized data are available from the corresponding author upon reasonable request.

\section{Authors' contributions}

SK collected and interpreted the data and wrote the first draft. SN contributed to the protocol's design and revised the manuscript. KT, YG, KK, TK, JS, and MW collected the data and revised the manuscript. All authors are accountable for all aspects of the work and have approved the final manuscript.

\section{Ethics approval and consent to participate}

This study was approved by the institutional review board of Jichi Medical University (Tochigi, Japan; 16-120). Written informed consent was obtained from all participants or their nearest relatives.

\section{Consent for publication}

Not applicable.

\section{Competing interests}

The authors declare that they have no competing interests.

\section{Publisher's Note}

Springer Nature remains neutral with regard to jurisdictional claims in published maps and institutional affiliations.

Received: 26 June 2018 Accepted: 13 August 2018

Published online: 28 August 2018

\section{References}

1. Levy B. Lactate and shock state: the metabolic view. Curr Opin Crit Care. 2006;12:315-21.
2. Hernandez G, Bruhn A, Castro R, Regueira T. The holistic view on perfusion monitoring in septic shock. Curr Opin Crit Care. 2012;18:280-6.

3. Garcia-Alvarez M, Marik P, Bellomo R. Sepsis-associated hyperlactatemia. Crit Care. 2014;18:503.

4. Aduen J, Bernstein WK, Khastgir T, Miller J, Kerzner R, Bhatiani A, et al. The use and clinical importance of a substrate-specific electrode for rapid determination of blood lactate concentrations. JAMA. 1994;272:1678-85.

5. Weil MH, Afifi AA. Experimental and clinical studies on lactate and pyruvate as indicators of the severity of acute circulatory failure (shock). Circulation. 1970;41:989-1001.

6. Bakker J, Coffernils M, Leon M, Gris P, Vincent JL. Blood lactate levels are superior to oxygen-derived variables in predicting outcome in human septic shock. Chest. 1991;99:956-62.

7. Singer M, Deutschman CS, Seymour CW, Shankar-Hari M, Annane D, Bauer $\mathrm{M}$, et al. The Third International Consensus Definitions for Sepsis and Septic Shock (Sepsis-3). JAMA. 2016;315:801-10.

8. Jansen TC, van Bommel J, Schoonderbeek FJ, Sleeswijk Visser SJ, van der Klooster JM, Lima AP, et al. Early lactate-guided therapy in intensive care unit patients: a multicenter, open-label, randomized controlled trial. Am J Respir Crit Care Med. 2010;182:752-61.

9. Ryoo SM, Lee J, Lee YS, Lee JH, Lim KS, Huh JW, et al. Lactate level versus lactate clearance for predicting mortality in patients with septic shock defined by Sepsis-3. Crit Care Med. 2018;46:e489-95.

10. De Backer D, Creteur J, Dubois MJ, Sakr Y, Koch M, Verdant C, et al. The effects of dobutamine on microcirculatory alterations in patients with septic shock are independent of its systemic effects. Crit Care Med. 2006:34:403-8.

11. Rhodes A, Evans LE, Alhazzani W, Levy MM, Antonelli M, Ferrer R, et al. Surviving Sepsis Campaign: International Guidelines for Management of Sepsis and Septic Shock: 2016. Intensive Care Med. 2017;43:304-77.

12. Fawer R, Justafre JC, Berger JP, Schelling JL. Intravenous glycerol in cerebral infarction: a controlled 4-month trial. Stroke. 1978:9:484-6.

13. Bayer AJ, Pathy MS, Newcombe R. Double-blind randomised trial of intravenous glycerol in acute stroke. Lancet. 1987;1:405-8.

14. Tsubokawa T, Katayama Y, Ishii S. Fructose-added glycerol (Glyceol) for therapy of elevated intracranial pressure: analysis of the side effects of long-term administration in a multi-institutional trial. Neurol Res. 1989;11: 249-52.

15. Katayama S, Nunomiya S, Wada M, Misawa K, Tanaka S, Koyama K, et al. Hyperlactatemia caused by intra-venous administration of glycerol: a case study. Indian J Crit Care Med. 2012;16:241-4

16. Bjorkman O, Gunnarsson R, Hagstrom E, Felig P, Wahren J. Splanchnic and renal exchange of infused fructose in insulin-deficient type 1 diabetic patients and healthy controls. J Clin Invest. 1989;83:52-9.

17. Atwell ME, Waterhouse C. Glucose production from fructose. Diabetes. 1971; 20:193-9.

18. Knaus WA, Draper EA, Wagner DP, Zimmerman JE. APACHE II: a severity of disease classification system. Crit Care Med. 1985;13:818-29.

19. Vincent JL, Moreno R, Takala J, Willatts S, De Mendonca A, Bruining H, et al. The SOFA (sepsis-related organ failure assessment) score to describe organ dysfunction/failure. On behalf of the working group on sepsis-related problems of the European Society of Intensive Care Medicine. Intensive Care Med. 1996;22:707-10.

20. Ahlborg G, Bjorkman O. Splanchnic and muscle fructose metabolism during and after exercise. J Appl Physiol. 1990;69:1244-51.

21. Youn JH, Bergman RN. Conversion of oral glucose to lactate in dogs. Primary site and relative contribution to blood lactate. Diabetes. 1991;40: 738-47.

22. Rosset R, Lecoultre V, Egli L, Cros J, Dokumaci AS, Zwygart K, et al. Postexercise repletion of muscle energy stores with fructose or glucose in mixed meals. Am J Clin Nutr. 2017;105:609-17.

23. Fox $1 \mathrm{H}$, Kelley WN. Studies on the mechanism of fructose-induced hyperuricemia in man. Metabolism. 1972;21:713-21.

24. Wang YM, van Eys J. Nutritional significance of fructose and sugar alcohols. Annu Rev Nutr. 1981:1:437-75.

25. Yu YL, Kumana CR, Lauder IJ, Cheung YK, Chan FL, Kou M, et al. Treatment of acute cerebral hemorrhage with intravenous glycerol. A double-blind, placebo-controlled, randomized trial. Stroke. 1992;23:967-71.

26. Node Y, Nakazawa S. Clinical study of mannitol and glycerol on raised intracranial pressure and on their rebound phenomenon. Adv Neurol. 1990; 52:359-63. 